\title{
Re-assessing the evidence about inhaled corticosteroids in chronic obstructive pulmonary disease
}

PMA Calverley

"For now we see through a glass darkly;"

Corinthians I: 13 v. 12

Research into chronic obstructive pulmonary disease (COPD), for so long the Cinderella disorder of respiratory medicine, has undergone something of a renaissance in the last 10 years, with an increased awareness of its high prevalence $^{1}$ as well as its growing importance as a cause of death in the developing world. ${ }^{2}$ Having achieved a measure of consensus on the most appropriate definition, ${ }^{3-5}$ more mechanistic studies have shown that inflammatory cell infiltration in the walls of large airways ${ }^{6}$ and the presence of pro-inflammatory cytokines in induced sputum are frequent findings in patients with COPD. ${ }^{78}$ The characteristics of the cellular and biochemical changes differ from those seen in asthma with a predominance of alveolar macrophages and a relative neutrophilia, whilst the lymphocytes in the airway wall show no evidence of the CD4+ predominance seen in asthmatic airways. ${ }^{6}$ Data from a variety of groups using different sampling methods confirm that active inflammation is present in the airways and in the alveoli $^{9}$ of patients with COPD at almost any stage of the disease. Inevitably, this begs the question of whether these processes can be modified and, given the substantial benefits seen in bronchial asthma, what might be the role of inhaled corticosteroids in the patient with COPD.

Data on the inflammatory changes seen in the airways of patients with COPD have been available for many years, ${ }^{10}$ although the scientific importance was not fully appreciated. Clinicians were aware that some patients with COPD improved dramatically after a course of oral corticosteroids - not just for exacerbations ${ }^{11}$ but even when clinically stable-and, as a result, empirical trials of corticosteroids have been recommended. ${ }^{12}$ Between 10\% and $20 \%$ of patients show a "response" to this therapy with a systematic meta-analysis favouring the former, ${ }^{13}$ a finding we have recently confirmed over a longer follow up period (L Davies, personal communication). One difficulty of this approach is the relatively high "signal to noise" problems even using the relatively reproducible forced expiratory volume in one second $\left(\mathrm{FEV}_{1}\right)$ manoeuvre to assess response. In our studies only patients with unequivocal large responses $(>400 \mathrm{ml})$ were likely to still show these benefits over a year of follow up and, not surprisingly, the corticosteroid trial itself has a relatively poor reproducibility. ${ }^{14}$ However, work from Canada ${ }^{15}$ does suggest that failure to respond to oral corticosteroids in patients with severe COPD ( $\mathrm{FEV}_{1} 36 \%$ predicted) selects a group of patients unlikely to respond to high dose inhaled corticosteroids, so the role of this test may have some practical value.

Open studies of patients with COPD receiving oral prednisolone and followed over many years suggested that those subjects who showed some initial improvement in $\mathrm{FEV}_{1}$ had a better survival. ${ }^{16}$ However, the side effects of such treatment would no longer be considered acceptable, especially given the known risks of corticosteroid myopathy and the increased mortality seen in patients receiving this treatment. ${ }^{17}$

From the mid 1980s attention has turned to the potential benefits of inhaled corticosteroid treatment and, in particular, whether the accelerated rate of decline of $\mathrm{FEV}_{1}$ characteristic of COPD can be modified by taking these drugs. These early studies were either uncontrolled, ${ }^{18} 19$ small, ${ }^{20}$ and/or included patients we would not consider to be unlikely to have COPD. ${ }^{20}{ }^{21}$ This year a large multicentre European study has reported significant improvements in peak expiratory flow (PEF), $\mathrm{FEV}_{1}$, symptoms, and exercise performance in patients with COPD not selected on the basis of corticosteroid responsiveness but treated with inhaled fluticasone propionate. ${ }^{22}$ These changes were not seen in a randomised control group but the follow up in this study was only six months, making comments on a more sustained effect of treatment impossible.

In this issue of Thorax van Grunsven and colleagues present a novel form of meta-analysis of the existing data on long term treatment with inhaled corticosteroids in COPD. ${ }^{23}$ They have carefully described their inclusion and exclusion criteria and have selected placebo controlled studies of at least two years duration. In searching the literature they identified a large previously unpublished trial from Paris $^{24}$ which makes a substantial contribution to the final data set. They addressed some the of deficiencies of the earlier studies by accepting only patients likely to have unequivocal COPD for re-analysis as outlined in their table 2 . The results lie halfway between a conventional meta-analysis and a wholly new publication, but they do make an important contribution to the debate about inhaled corticosteroids and COPD.

Clearly this approach has limitations which must be considered when giving weight to the authors' conclusions. The measurement intervals during the follow up in one of the trials ${ }^{20}$ were two monthly rather than three monthly, and the resulting data points of the study were obtained by interpolation. There are far more pre-bronchodilator $\mathrm{FEV}_{1}$ data than post-bronchodilator data available, which is unfortunate as the latter are less subject to day to day variation in airway smooth muscle tone and represent the "non-bronchodilator" effect which is the potentially important benefit of prolonged anti-inflammatory activity. Different doses of different inhaled corticosteroids were used, although it is unlikely that this is important as the majority received high dose treatment via a metered dose inhaler. However, it is a pity that data about skin bruising and adrenal function in the active and placebo groups are not available. A further difficulty, common to all studies of this type where complex statistics are needed to control for the many relevant co-variants, is the difficulty in accepting that the data in the figures correspond to the apparently very significant differences in outcome variables recorded in the text. This is exaggerated by the different numbers of measurements available at each time point.

Despite these reservations, the results do appear to be clear and the post-bronchodilator $\mathrm{FEV}_{1}$ data do support the conclusions drawn. In this population of moderately severe patients treatment with high doses of inhaled corticosteroids reduced the observed rate of decline in $\mathrm{FEV}_{1}$ by approximately $34 \mathrm{ml} /$ year. In general, the higher the baseline $\mathrm{FEV}_{1}$ the greater the effect likely to be seen in patients taking $\beta$ agonists. 
As the authors acknowledge, this last conclusion is based on relatively weak evidence and should not be overinterpreted. However, contrary to earlier reports, ${ }^{25}$ it is likely that the use of $\beta$ agonists is not having any deleterious effect. The usual rate of decline in $\mathrm{FEV}_{1}$ in a COPD population such as this is approximately $50-60 \mathrm{ml}$ per year, with the most rapid decline exceeding $80 \mathrm{ml}$ per year, so it would have been helpful had the authors been able to report an absolute rate of decline in their two populations. However, a linear function could not be fitted to the $\mathrm{FEV}_{1}$ data. This emphasises the need for large sample sizes to derive the most appropriate statistics in populations such as this. A more subtle methodological problem remains. In the Paggario study ${ }^{22}$ and in the preliminary report of Euroscop, the three year trial of inhaled corticosteroids in smokers with COPD, an early effect was seen after instituting treatment. Thereafter, there did not seem to be any further change in lung function. The impact of this pattern of response when calculating the rate of decline in lung function can be very misleading, particularly if the follow up period is relatively brief. It is difficult in the present analysis to be sure whether such an effect was present and certainly the authors do not report it. Nonetheless, its detection is of considerable importance in understanding how treatment with inhaled corticosteroids may be working and how long the benefits may be sustained.

Two other important negatives are worth noting in this new study. Firstly, no effect of smoking status was seen in this population, contrary to the initial reports from Euroscop. Unfortunately, greater disease severity, a less satisfactory description of smoking status without its objective confirmation, or simply a type 2 statistical error may explain this finding. Secondly, exacerbations defined in terms of attendance for corticosteroid and/or antibiotic treatment did not differ between the treatment and placebo groups. It is difficult to be certain whether this definition applied equally to all three populations reported and certainly differences in the management of acute exacerbations are likely to be present between the Netherlands and France. Careful studies with an appropriate prospective definition of exacerbation are still needed in this area.

Where does this leave us? The present study does provide clear evidence that inhaled corticosteroids may modify the rate of decline in $\mathrm{FEV}_{1}$ in patients with moderately severe COPD, but the dose to be used, duration of treatment, risk of longer term side effects, and the time course of their action remain unresolved. It does set the stage for the publication/presentation of the results of the longer term (over three years) prospective randomised placebo controlled studies of inhaled corticosteroids (Euroscop, ISOLDE, Copenhagen City Lung Study) this autumn and of the second Lung Health Study next year. Hopefully, these will clarify many of the issues van Grunsven and colleagues have raised as well as confirming their positive conclusions. Let us hope, like St Paul, that: "now I know in part but then I shall know even as I am known".

University Clinical Departments at Aintree,

P M A CALVERLEY

Fazakerley Hospital,

Liverpool L9 7 AL, UK

1 Strachan DP. Epidemiology: a British perspective. In: Calverley PMA, Pride NB, eds. Chronic obstructive pulmonary disease. London: Chapman and Hall, 1995: 47-68.

2 Murray CJL, Lopez AD. Mortality by cause for eight regions of the world: global burden of disease study. Lancet 1997;349:1269-76.

3 Siafakas NM, Vermeire P, Pride NB, et al. Optimal assessment and management of chronic obstructive pulmonary disease (COPD). Eur Respir $\mathcal{F}$ 1995;8:1398-420.

4 American Thoracic Society. Standards for the diagnosis and care of patients with chronic obstructive pulmonary disease. Am f Respir Crit Care Med 1995;152:S77-121.

5 Standards of Care Committee of the British Thoracic Society. BTS guidelines for the management of chronic obstructive pulmonary disease. Thorax 1997;52(Suppl 5):S1-28.

6 O'Shaughnessy TC, Ansari TW, Barnes NC, et al. Inflammation in bronchial biopsies of subjects with chronic bronchitis: inverse relationship of CD8+ T

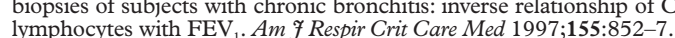

7 Keatings VM, Collins PD, Scott DM, et al. Differences in interleukin-8 and tumour necrosis factor- $\alpha$ in induced sputum from patients with chronic obstructive pulmonary disease or asthma. Am 7 Respir Crit Care Med 1996;153:530-4.

8 Keatings VM, Jatakanon A, Worsdell YM, et al. Effects of inhaled and oral glucocorticoids on inflammatory indices in asthma and COPD. Am $\mathcal{F}$ Respir Crit Care Med 1997;155:542-8.

9 Saetta M, Ghezzo H, Kim WD, et al. Loss of alveolar attachments in smokers. A morphometric correlate of lung function impairment. Am Rev Respir Dis 1985;132:894-900.

10 Glynn AA, Michaels L. Bronchial biopsy in chronic bronchitis and asthma. Thorax 1969;24:176-9.

11 Albert RK, Martin TR, Lewois SW, et al. Controlled trial of methlyprednisolone in patients with chronic bronchitis and acute respiratory insufficiency. Ann Intern Med 1980;92:753-8.

12 Nisar M, Walshaw MJ, Earis JE, et al. Assessment of reversibility of airway obstruction in patients with chronic obstructive airways disease. Thorax 1990;45:190-4.

13 Callahan CM, Dittus RS, Katz BP. Oral corticosteroids therapy for patients with stable chronic obstructive pulmonary disease. Ann Intern Med 1991;114:216-23.

14 Spence DPS, Rimington LD, Nisar M, et al. Corticosteroid trial reproducibility in COPD. Thorax 1994;49:392P (abstract).

15 Bourbeau J, Rouleau MY, Boucher S. Randomised controlled trial of inhaled corticosteroids in patients with chronic obstructive pulmonary disease. Thorax 1998;53:477-82.

16 Postma DS, Peters I, Steenhuis EJ, et al. Moderately severe chronic airflow obstruction. Can corticosteroids slow down progression? Eur Respir $\mathcal{F}$ 1998;1:22-6.

17 Decramer M, de Bock V, Dom R. Functional and histologic picture of steroid-induced myopathy in chronic obstructive pulmonary disease. $A m \mathcal{F}$ Respir Crit Care Med 1996;153:1958-64.

18 Weir DC, Robertson AS, Gove RI, et al. Non-asthmatic chronic airflow obstruction: can inhaled corticosteroids slow down disease progression? Thorax 1998;43:857P (abstract).

19 Dompeling E, van Schayck CP, Grunsven PM, et al. Slowing the deterioration of asthma and chronic obstructive pulmonary disease observed during tion of asthma and chronic obstructive pulmonary disease observed during
bronchodilator therapy by adding inhaled corticosteroids. A 4-year bronchodilator therapy by adding inhaled cor
prospective study. Ann Intern Med 1993;118:770-8.

20 Renkema TE, Schouten JP, Koeter GH, et al. Effects of long-term treatment with corticosteroids in COPD. Chest 1996;109:1156-62.

21 Kerstjens HAM, Brand PLP, Hughes MD and the Dutch CNSLD Group. A comparison of bronchodilator therapy with and without inhaled corticosteroid therapy in obstructive airways disease. N Engl f Med 1992;327: 1413-9.

22 Paggiaro PL, Dahle R, Bakran I, et al. Multicentre randomised placebo-controlled trial of inhaled fluticasone propionate in patients with chronic obstructive pulmonary disease. Lancet 1998;357:773-80.

23 Van Grunsven PM, van Schayck CP, Derenne JP, et al. Long term effects of inhaled corticosteroids in chronic obstructive pulmonary disease: a meta-analysis. Thorax 1999;54:7-14

24 Derenne JP. Effects of high dose inhaled beclomethasone on the rate of decline in $\mathrm{FEV}_{1}$ in patients with chronic obstructive pulmonary disease: results of a 2 years prospective multi-centre study. Am 7 Respir Crit Care Med 1995; 157:A463 (abstract).

25 Van Schayck CP, Dompeling E, van Herwaarden CLA, et al. Bronchodilator treatment in moderate asthma or chronic bronchitis: continuous or on demand? A randomised controlled study. BMF 1991;303:1426-31. 